\title{
The Contingent Role of Centrality in IT Network Governance: An Empirical Examination
}

\author{
Simon Trang \\ Chair for Information Management \\ University of Göttingen \\ strang@uni-goettingen.de \\ Sebastian Zander \\ Chair for Information Management \\ University of Göttingen \\ szander1@uni-goettingen.de \\ Lutz M. Kolbe \\ Chair for Information Management \\ University of Göttingen \\ lkolbe@uni-goettingen.de
}

\begin{abstract}
Since the importance of collaboration across organizational boundaries for firms' competitive success continues to grow dramatically, research on inter-organizational relationships has become prominent in business and information systems (IS) research. Particularly interorganizational networks have been widely recognized by both academics and practitioners as an important form of multi-organizational governance. Those networks rely heavily on integrated information systems in order to generate value from co-creation, co-development, and coinnovation. Therefore, the integration of IS across partnering organizations has become the backbone of collaboration in inter-organizational networks. Despite the efforts invested in the field of IT governance arrangements, research still lacks empirical evidence on the relationship between governance choices and different internal and external network factors and their influence on governance effectiveness. Thus, this study sets out to expand the understanding of how network organizations can effectively develop and manage IS integration in order to cocreate value. It contributes with a characterization of IT network governance arrangements along the dimension from highly centralized to highly decentralized IT related decision making in networks. Moreover, by drawing on contingency theory this paper develops a theoretical model proposing effective governance arrangements according to six contingency variables. A multiple case study methodology is applied in order to validate the theoretical relationships, and the data supports the basic structure of the research model. Our findings suggest that network size, network structure centralization, functional diversity, network trust, IT infusion, and IT competence are important factors for the understanding of effective IT governance arrangements in inter-organizational networks. The paper offers insights into the causal mechanisms behind the theoretical relationships and is a first step towards a more differentiated perspective on contingent governance structures in inter-organizational networks.
\end{abstract}

Keywords: IT network governance, inter-organizational networks, contingency theory 


\section{Introduction}

As a result of the pressure of globalized markets, organizations in the private as well as public sectors increasingly operate as part of highly distributed ecosystems (Grant \& Tan 2013). Thus, organizations are compelled to remodel their business relationships and establish collaboration across organizational boundaries. This development has resulted in arrangements that are operationalized in interorganizational networks. These crossorganizational activities are expected to lower costs, create higher efficacy, and increase overall profitability (Provan \& Kenis 2008). The premise for operating within such value-generating networks is the application of advanced information and communication technologies, as IT resources play a critical role in managing collaborative structures. However, IT resources per se are not a source of sustained value; in fact, an enhanced value from this collaborative IT is contingent upon its governance within a network of organizations (Prasad et al. 2013). Our understanding of IT network governance follows Croteau and Bergeron (2009), who define IT network governance as "the authority and accountability frameworks put in place to encourage the efficient and effective use of IT when sustaining electronic exchanges among business partners."

When reviewing the emerging stream of IS literature on inter-organizational governance arrangements, two main research gaps become apparent. First, studies describe singular concepts of current governance practices rather than find overarching classifications of different types. For example, Chong and Tan (Chong \& Tan 2012) study IT-related governance arrangements in a health-care-network setting and analyze properties of a federal governance approach. A similar proceeding can be found in Prasad et al. (2011), who identify co-created IT steering committees, inter-organizational lateral communication systems, inter-organizational performance managements, and co-created operational systems committees as four broad IT governance conceptions; however they offer no view on the classification of different governance modes. Second, although the establishment of IT network governance structures has already been related to success measures (as can be found in an empirical study of Prasad et al. 2013), prior studies neglect the necessity of a fit between governance arrangements and network-specific factors. Following the argumentation of contingency theory, there is no best way to govern the IT, but rather the optimal choice is dependent on the internal and external factors specific for each network. The importance of this contingent perspective for the context of IT network governance has already been stressed by De Haes and Van Grembergen (2012) and King (King 2013). While prominent studies from the field of IT governance (Sambamurthy \& Zmud 1999; Brown \& Magill 1998) as well as studies on network governance (Provan \& Kenis 2008; Span et al. 2011) use contingency theory in order to explain how organizational structures are shaped by internal and external factors, to the best of our knowledge, there is no study translating this to the governance of IT resources in interorganizational networks. Both gaps in current IT network governance research led us to the formulation of the following research questions:

RQ1: What IT governance arrangements can be identified in inter-organizational networks?

RQ2: How should IT governance arrangements be shaped under the consideration of contingency factors?

The objective of this study is to enhance the understanding of IT governance structures within an inter-organizational network context. For research in the field of IT network governance, it is important to not only consider structures and configurations of accountabilities and decision making, but 
also, the way that inter-organizational governance situations are shaped by dynamic factors of the environment in which governance practices are executed (Grant \& Tan 2013). Therefore, we use contingency theory in order to develop a model for predicting effective IT governance archetypes, with centrality of decision making as the core concept for classification.

The remainder of the paper is structured as follows. The next chapter starts with a review of literature on IT network governance, followed by the identification and description of IT network governance archetypes (RQ1). In Section 3 we derive the underlying model for this study and identify relevant factors from literature on contingency variables in the fields of IT governance and network governance (RQ2) Furthermore, an explanatory multiple case study approach was chosen to validate the theoretical archetypes and the contingency model. We close with reviewing and discussing the results from our case studies and, finally, derive further research recommendations.

\section{Theoretical Background}

\section{Reviewing IT network governance}

The term IT governance originates in organizational studies of large businesses. A widely acknowledged understanding is provided by Weill and Ross (2004), who define IT governance as "specifying the framework for decision rights and accountabilities to encourage desirable behavior in the use if IT." In other words, IT governance is not about single IT-related decisions but should rather ensure that the right people at the right place make the right decisions. If we leave the organizational level and translate this to the network level, we can see that this understanding is also applicable in the context of interorganizational networks. We also have implicit governance in loosely coupled networks with no formal structures. This, however, does not necessarily imply either effectiveness or efficiency.
Steering inter-organizational IT is discussed in an emerging stream of IS literature (Grant \& Tan 2013; De Haes \& Van Grembergen 2012) and is seen as separate from traditional intra-organizational IT governance. Due to the nature of interorganizational networks as loosely coupled and geographically distributed entities with polycentric power distribution and a low degree of formalization (Alter \& Hage 1993), organizational structures are fundamentally different and aspects such as trust, power, contracts, and open communication play an even more important role (Xiao et al. 2012). Findings and practices from intraorganizational IT governance implementations can therefore not be directly translated and must be rethought (Zarvić et al. 2012).

In the case of governance of IT in a network context, the unit of analysis is common IT resources supporting the interorganizational collaboration. In order to assure effectiveness, joint governance structures are necessary (Prasad et al. 2013).

\section{Archetypes of IT network governance}

Studying different structures of IT-related decision making within big firms and exploring their relationship to corporate success is one of the core streams in IT governance research (Brown \& Grant 2005). A typical characteristic of these structures is the degree of centralization of responsibilities and accountabilities. From a bipolar perspective, organizational placement of decision-making authority can be classified along the dimension of highly centralized to highly decentralized (Brown \& Grant 2005). Strict centralized governance concentrates decision authorities at a centralized position (e.g., top management or centralized IT specialist), whereas decentralized governance delegates decision authorities on a business-unit or process level (Brown \& Grant 2005). Centralization facilitates organizations to profit from enterprise-wide integration, standards, and operational efficiency; 
decentralization, on the other hand, leads to higher flexibility in the customization of solutions and, therefore, improves the responsiveness to business needs (Brown \& Grant 2005).

The degree of centrality of decision making can also be translated to the context of inter-organizational networks. In general, three different archetypes can be distinguished according to their degree of centrality, i.e., decentralized, hybrid, and centralized. While in practice IT network governance is likely to occur in between the continuum, these fundamental forms describe ideal-typical instances. Table 1 provides a short description of each archetype. In practice, we can see all three kinds of governance archetypes (see Table $1)$. What we answer in the next section is the question of which option is best for which organization and, in turn, how the choice of governance mode relates to success.

\section{Developing a Contingency Model for IT Network Governance}

Contingency theory has its roots in organizational sciences and basically posits that there is no single best solution that fits all cases. More specifically, contingency theory argues that the best configuration depends on internal and external factors (Weill \& Olson 1989). Translating this perspective to IT network governance archetypes, the effectiveness of a centralized, hybrid, or decentralized archetype depends on the context of the specific network.

\section{Table 1 - Description of IT network governance archetypes}

\begin{tabular}{|c|c|}
\hline Archetypes & Descriptions \\
\hline 1. Decentralized & $\begin{array}{l}\text { In the decentralized archetype, IT-related decisions are delegated to each } \\
\text { individual organization. Single decisions that affect other organizations may be } \\
\text { negotiated among this group; however, there is no coordination with other } \\
\text { network members. This form of governance allows for a high degree of } \\
\text { responsiveness since decisions can be made flexibly without the consideration } \\
\text { of long-term agreements and network rules. Decentralized forms of IT } \\
\text { governance can, for example, be found in the descriptions of Markus and Bui } \\
\text { (2012) of inter-organizational coordination hubs. }\end{array}$ \\
\hline 2. Hybrid & $\begin{array}{l}\text { If networks have both centralized and decentralized forms of decision making, } \\
\text { this is classified as hybrid. Concrete instances of this archetype include the } \\
\text { federal approach (Weill \& Ross 2004). While there is an agreement among all } \\
\text { network members for fundamental IT, there are no strict or binding rules, and } \\
\text { members are relatively free to implement their own IT. Such hybrid decision } \\
\text { making can, e.g., be found in a study of Chong and Tan (2012) who describe } \\
\text { an opportunity-driven network of eight organizations in the health industry. }\end{array}$ \\
\hline 3. Central & $\begin{array}{l}\text { For the centralized archetype, IT-related decisions are bundled at a centralized } \\
\text { entity of the network. It has a dedicated authority to make decisions binding for } \\
\text { all members. This entity can have different shapes. For example, there can be } \\
\text { a lead organization that sets the rules for decision making. Another example is } \\
\text { a dedicated network administrative organization set up by the network as } \\
\text { described in Provan and Kenis (2008). Communication and coordination } \\
\text { regarding IT-related topics occurs mainly through this entity. The strong } \\
\text { coordination may lead to a higher degree of standardization and efficiency in } \\
\text { information exchange. Xiao et al. (2013), for instance, identify centralized IT } \\
\text { network governance modes in networks of the automotive industry. }\end{array}$ \\
\hline
\end{tabular}




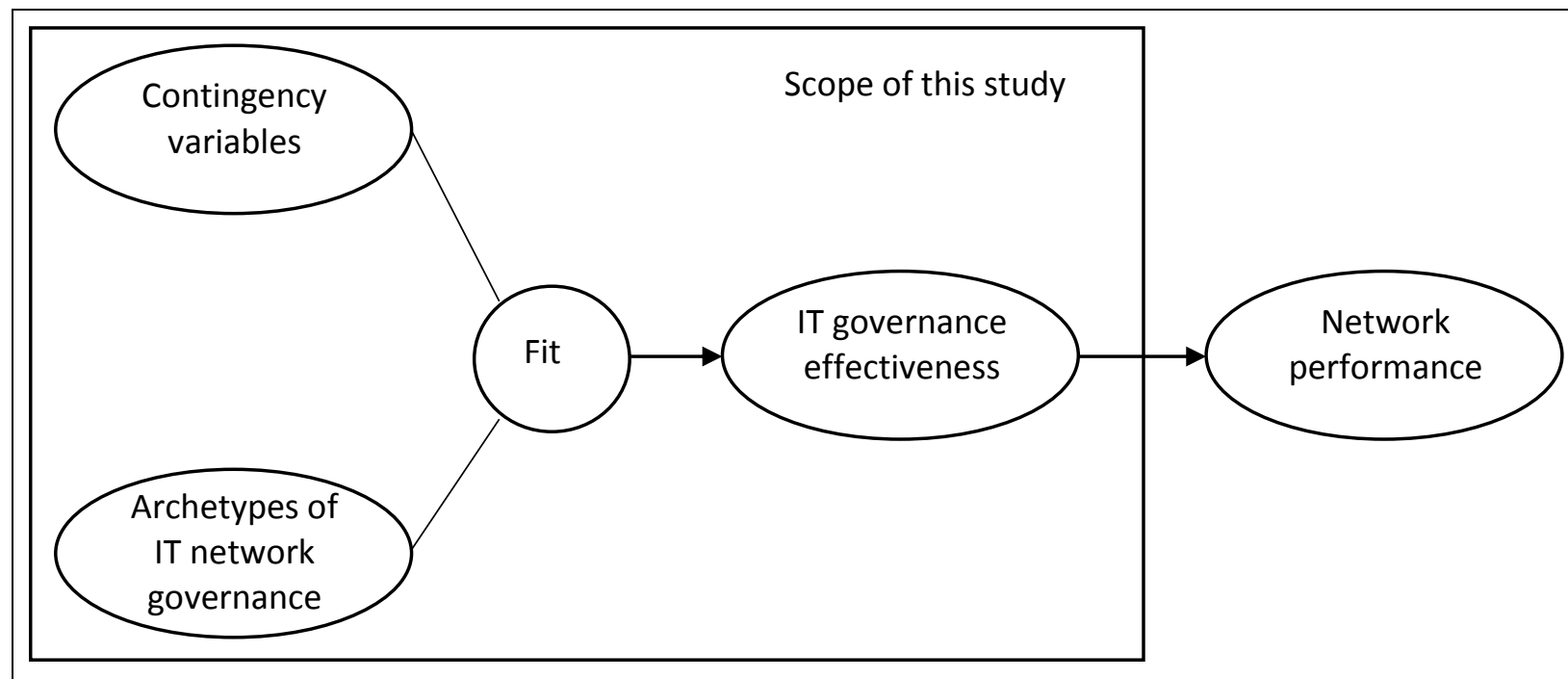

\section{Figure 1 - Research model for this study}

Borrowing from Weill and Olsen's (1989) generic research model for the application of contingency theory in the IS field, we derive the underlying model for this study (see Figure 1). We propose that an archetype of IT network governance only positively influences IT governance effectiveness if there is a fit with contingency variables. We define fit according to the matching approach specified in Venkatraman (1989), in which fit is a theoretically defined match between two related variables. The basic idea is that each contingency variable differently matches with a governance archetype (see Figure 2). For example, assume that networks with a high number of members would benefit from centralized governance. If a large network indeed has centralized IT network governance, we assume a positive fit and, thus, a high degree of IT governance effectiveness. In turn, if a small network has centralized IT network governance, we assume a negative fit and, thus, a low degree of IT network governance effectiveness.

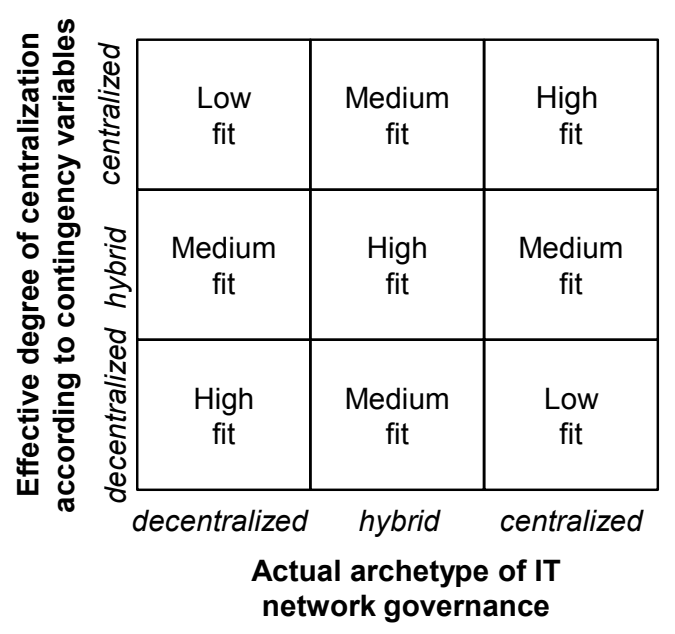

Figure 2 - Conceptualization of fit as matching between actual IT network governance archetype and the effective degree of centralization according to the contingency variables 
As depicted in Table 2, we identified six relevant factors from a literature review on contingency variables in the fields of IT governance and network governance. It is argued that each variable differently matches to the degree of governance centralization. We found that network size, network structure centralization, functional diversity, trust, IT infusion, and IT competence are important for the allocation of decision rights in inter-organizational networks. For each variable an effective degree of centralization is derived from literature.

\section{Table 2 - Contingency variables and their effective degree of IT network governance} centralization

\begin{tabular}{|c|c|c|c|c|c|}
\hline \multirow{2}{*}{$\begin{array}{l}\text { Contingency } \\
\text { variables }\end{array}$} & \multirow{2}{*}{ Description } & \multirow{2}{*}{ References } & \multicolumn{3}{|c|}{$\begin{array}{l}\text { Effective degree IT network } \\
\text { governance centralization }\end{array}$} \\
\hline & & & Decentral & Hybrid & Centralized \\
\hline Network size & $\begin{array}{l}\text { Number of } \\
\text { organizations } \\
\text { involved in a } \\
\text { network }\end{array}$ & $\begin{array}{l}\text { (Provan \& Kenis 2008) }^{b}, \\
(\text { Ein-dor \& Segev 1982) } \\
\left(^{a} \text {, }\right.\end{array}$ & Small & Medium & Large \\
\hline $\begin{array}{l}\text { Network } \\
\text { structure } \\
\text { centralization }\end{array}$ & $\begin{array}{l}\text { Determines where } \\
\text { the locus of } \\
\text { authority resides } \\
\text { in the network }\end{array}$ & $\begin{array}{l}\text { (Ein-dor \& Segev 1982) } \\
\text { (Sambamurthy \& Zmud }^{\text {, }} \\
\text { 1999) }^{a}\end{array}$ & Low & Medium & High \\
\hline $\begin{array}{l}\text { Functional } \\
\text { diversity }\end{array}$ & $\begin{array}{l}\text { Diversity in terms } \\
\text { of know-ledge, } \\
\text { capabilities, and IT } \\
\text { needs of the } \\
\text { network members }\end{array}$ & $\begin{array}{l}(\text { Span et al. 2011) } \\
\left(^{b} \text {, }\right. \\
\text { Dowse \& Lewis 2009) }^{a}\end{array}$ & High & Medium & Low \\
\hline Network trust & $\begin{array}{l}\text { Trust among } \\
\text { network members }\end{array}$ & (Provan \& Kenis 2008) $^{b}$ & High & Medium & Low \\
\hline IT infusion & $\begin{array}{l}\text { Degree to which a } \\
\text { network is } \\
\text { dependent on IT } \\
\text { to carry out core } \\
\text { operations }\end{array}$ & $\begin{array}{l}\text { (Brown \& Magill 1998) }^{a} \\
\left(^{\text {Sullivan 1985) }}\right.\end{array}$ & High & Medium & Low \\
\hline IT competence & $\begin{array}{l}\text { IT competence of } \\
\text { the network } \\
\text { members }\end{array}$ & $\begin{array}{l}\text { (Provan \& Kenis 2008) }^{b}, \\
\text { (Sambamurthy \& Zmud } \\
1^{1999)^{a}} \text {, (Brown \& Magill } \\
\text { 1998) }^{\mathrm{a}}\end{array}$ & High & Medium & Low \\
\hline
\end{tabular}

(a) indicates IT governance literature; (b) indicates literature from network governance

Network size. Network size refers to the number of organizations within a network. The first variable was found to be relevant in both IT governance and network governance research. Since size is an important determinant of other context variables, it should be also related to IT structure (Tavakolian 1989). Ein-Dor and
Segev (1982) show in an organizational context that size is positively related to the degree of centralization of the IT function. Regarding network governance, a fundamental problem is that the needs and activities of multiple organizations must be accommodated and coordinated. As the number of organizations within a network 
grows, the number of potential relationships increases exponentially and thus governance becomes more complex. With participants ignoring network issues and spending time to coordinate across multiple organizational boundaries, shared network governance becomes inefficient (Faerman et al. 2001; Staber 1998). An increasing number of network members increase the relations among them exponentially, which in turn increases governance complexity. Accordingly, networks with a small network size allow decentralized coordination of ITrelated decisions, whereas the complexity of large networks can only be managed centrally. Therefore, we argue that large networks tend to have centralized IT governance practices, whereas networks with a small number of participants will follow a decentralized approach.

Functional diversity. The second factor, functional diversity, refers to the diversity in terms of knowledge, capabilities, and IT needs of the network members. The functional diversity of organizations participating in the same network is relevant to how the network can best be governed (Span et al. 2011). An increasing amount of diversity leads to greater uncertainty, which results in the push for bottom-up governance mechanisms in order to react flexibly (Lawrence \& Lorsch 1967). Thus, a high degree of diversity fosters a more decentralized governance practice. Previous empirical IT governance research (Dowse \& Lewis 2009) also indicates that organizations with a high degree of diversity among business units also prefer more decentralized archetypes of IT governance because the higher the diversity, the higher the individual demands. On the other hand, the more homogenous the network members and their IT needs are, the more synergies can be gained, which can be facilitated through a centralized mode of governance.

Network trust. Trust at a general level can be explained as the willingness to accept vulnerability based on positive expectations about other's intentions or behaviors
(McEvily et al. 2003). In the context of interorganizational collaboration, trust is a critical factor for network success because it reduces costs and improves performance (Powell 1990; Zaheer et al. 1998). In the case of centralized networks, vulnerability is reduced due to formalized and dedicated rule-based governance systems. In decentralized networks with no dedicated governance authority and a lack of formalized decision making, trust is the foundation for collaboration. Since pervasive trust leads to shared expectations about intentions and behaviors among network members, a decentralized approach is likely to be efficient. To the contrary, in the absence of trust, shared governance practices will not be effective due to the missing basis for collaboration (Provan \& Kenis 2008). Consequently, a low level of trust will lead to more formalization and thus to centralized IT governance.

Network structure centralization. This factor refers to the degree of centralization. It determines where the locus of authority resides for making decisions. Previous studies find that organizational structures are influencing IT governance practices (Brown \& Magill 1998; Ein-dor \& Segev 1982; Peterson 2004; Sambamurthy \& Zmud 1999). In an organizational context, companies with centralized governance modes tend to also have centralized IT governance structures, whereas a decentralized form of governance leads to a more decentralized form of IT governance practices. We assume that these coherences are also true for the government in networks. Thus, centralized IT network governance is more likely to appear in centrally governed networks, while a decentralized mode of network governance will lead to a more decentralized IT network governance approach.

IT infusion. This factor describes the degree to which a network is dependent on IT to carry out core operations. From a resource dependence theory-based view, Brown and Magill (1998) find that 
The Contingent Role of Centrality in IT Network Governance: An Empirical Examination/ Trang et al.

organizational units try to avoid dependencies and seek autonomy if a resource is identified as a key success factor, which results in a decentralized form of governance. Sullivan (1985) as well as Ward and Peppard (2002) acknowledge these findings with regard to IT governance practices. Transferred to IT governance in a network context, we argue that IT will be governed centrally when the relevance of IT is less important. If the IT is perceived as a relevant factor for performing business processes, organizations are motivated to integrate and control IT (Chatterjee \& Ravichandran 2013), and will thus result in a more decentralized form of governance.

IT competence. The last factor describes the IT competence of network members. Different levels of competences require different network governance practices (Provan \& Kenis 2008). In an IT-governance context, previous studies find that the absence of knowledge and experience regarding IT hampers decentralized IT decision making in organizations. This leads to a more centralized approach, with decisions made by experts or specialists (Brown \& Grant 2005). In contrast, a high level of IT competence is associated with a decentralized form of IT governance (Brown \& Magill 1998; Sambamurthy \& Zmud 1999). Thus, in a network context, decentralized IT governance practices are more likely to appear if the level of IT competence is high among network members, while missing or low IT competences will result in centralized IT governance modes.

\section{Case Study Research Design}

An explanatory case study approach is chosen in order to validate the theoretical archetypes and explain differences in the degree of IT network governance centralization. The case study method is suitable for studying a current phenomenon deeply and timely, especially when boundaries are vague and context may play an important role (Yin 2009). In general, case studies are favorable in early stages of research on new topics for which existing theories/models seem inadequate (Eisenhardt 1989). As research on IT network governance is in an early stage (Trang et al. 2013) and the concept under study, i.e., centrality of IT-related governance structures, is novel, we have come to the conclusion that case study methodology is the most appropriate method for this research. The case studies were conducted in light of the contingency model. The goal was to collect data that, first, validates the archetypes of IT network governance and, second, validates the explanations of the relationships between the contingency factors and their influence on the centrality of decision making. In order to ensure the rigorousness of our research, our research design followed the steps suggested by Paré (2004). An overview of all stages and activities is described in Table 3.

Following a diverse case-sampling strategy, we identified networks according to their anticipated characteristics in order to obtain a high degree of variance along our dimensions. Between January and April 2013, we performed case studies in five German networks. An overview of all case sites is found in Table 4. The central instrument for data collection was semistructured interviews. This form of interview allows for question adjustments based on the situation. We developed an interview guideline based on our research model. The questions circle around the network and its development, the role of IT for the collaboration, IT-related decision-making structures, and, finally, each contingency factor. The interviews last between 25 and 55 minutes and were recorded with a voice recorder. The process of transcription and analysis was supported using the tool MaxQDA11. Our coding procedure followed the qualitative content analysis suggested by Mayring (2007). According to the predefined model, we identified relevant dimensions of all theoretical constructs and applied a deductive analysis method. For IT governance effectiveness, we also used a structured questionnaire. The instrument is 
based on a governance-effectiveness scale as suggested by Weill and Ross (2004). It covers four areas of IT network governance, i.e. cost effective use of network IT, effective use of network IT for growth, for asset utilization, and for business flexibility. The assessment bases on the outcome importance for the network and the influence of the IT network governance.

\begin{tabular}{|c|c|c|}
\hline Stage & Activities & Description \\
\hline \multirow[t]{3}{*}{$\begin{array}{l}\text { 1. Design of } \\
\text { the case } \\
\text { study }\end{array}$} & Prior theorizing & $\begin{array}{l}\text { The case study is based on the predefined contingency model, } \\
\text { which consists of contingency factors, governance archetypes, and } \\
\text { a performance variable }\end{array}$ \\
\hline & Unit of analysis & $\begin{array}{l}\text { IT-related decision making of organizations at the network level, } \\
\text { including structures, processes, and relational mechanisms }\end{array}$ \\
\hline & $\begin{array}{l}\text { Sampling } \\
\text { strategy }\end{array}$ & $\begin{array}{l}\text { Case selection in the multiple case design follows a diverse case- } \\
\text { sampling strategy, i.e., achieving maximum variance along the } \\
\text { relevant dimensions }\end{array}$ \\
\hline \multirow[t]{2}{*}{$\begin{array}{l}\text { 2. Conduct } \\
\text { the case } \\
\text { study }\end{array}$} & $\begin{array}{l}\text { Data } \\
\text { triangulation }\end{array}$ & $\begin{array}{l}\text { Multiple sources of evidence are used and consolidated, which } \\
\text { includes semi-structured interviews, questionnaires, and documents } \\
\text { from the case sides (internal and external) }\end{array}$ \\
\hline & $\begin{array}{l}\text { Theoretical } \\
\text { saturation }\end{array}$ & $\begin{array}{l}\text { Theoretical saturation is reached after five case studies since we } \\
\text { reached high variance in our variables }\end{array}$ \\
\hline \multirow{3}{*}{$\begin{array}{l}\text { 3. Analysis of } \\
\text { the case } \\
\text { study } \\
\text { evidence }\end{array}$} & $\begin{array}{l}\text { Early steps in } \\
\text { data analysis }\end{array}$ & $\begin{array}{l}\text { Interviews are transcribed and analyzed. Information is structured } \\
\text { and recorded in a project database }\end{array}$ \\
\hline & $\begin{array}{l}\text { Within-case } \\
\text { analysis }\end{array}$ & $\begin{array}{l}\text { Qualitative content analysis and pattern matching are used to } \\
\text { evaluate the predefined constructs, see (Mayring 2007) }\end{array}$ \\
\hline & $\begin{array}{l}\text { Cross-case } \\
\text { analysis }\end{array}$ & Differences in constructs are analyzed across the cases \\
\hline $\begin{array}{l}\text { 4. Writing up } \\
\text { the case } \\
\text { study report }\end{array}$ & $\begin{array}{l}\text { Case study } \\
\text { report }\end{array}$ & Reports are written down according to a standardized guideline \\
\hline
\end{tabular}

Table 4 - Summary of case sites
\begin{tabular}{|l|l|l|l|l|l|}
\hline Characteristics & \multicolumn{5}{|c|}{ Network } \\
\cline { 2 - 6 } & Case A & Case B & Case C & Case D & Case E \\
\hline Branch & Real estate & Automotive & Public sector & Public sector & Energy \\
\hline $\begin{array}{l}\text { Number of } \\
\text { members }\end{array}$ & Approx. 100 & 15 & Approx. 300 & 35 & 5 \\
\hline $\begin{array}{l}\text { Areas of } \\
\text { cooperation }\end{array}$ & $\begin{array}{l}\text { Marketing, } \\
\text { exchange of } \\
\text { experience }\end{array}$ & $\begin{array}{l}\text { Primary buying, } \\
\text { marketing, } \\
\text { shared services }\end{array}$ & $\begin{array}{l}\text { Production } \\
\text { of digital } \\
\text { content }\end{array}$ & $\begin{array}{l}\text { Production } \\
\text { of digital } \\
\text { content }\end{array}$ & $\begin{array}{l}\text { Supply of } \\
\text { resources }\end{array}$ \\
\hline Interviewees & $\begin{array}{l}\text { CEO at network } \\
\text { organization, } \\
\text { CEO at member } \\
\text { organization }\end{array}$ & $\begin{array}{l}\text { ClO at network } \\
\text { organization, } \\
\text { ClO at member } \\
\text { organization }\end{array}$ & $\begin{array}{l}\text { Network } \\
\text { coordinator, } \\
\text { ClO at member } \\
\text { organization }\end{array}$ & $\begin{array}{l}\text { ClO at } \\
\text { member } \\
\text { organization }\end{array}$ & $\begin{array}{l}\text { ClO at } \\
\text { member } \\
\text { organization }\end{array}$ \\
\hline
\end{tabular}

Research results can only be claimed to add to the knowledge base of a field of study if generalizability, reliability, and validity are assured (Yin 2009). The case study design has been informed by a previously developed theory. Our model proposes relationships that are compared to the empirical results of the multiple case 
The Contingent Role of Centrality in IT Network Governance: An Empirical Examination/ Trang et al.

studies, thus we argue for analytical generalization. The quality of a qualitative empirical inquiry is usually described within four established categories: construct validity, internal validity, external validity, and reliability. In conducting our research, we paid particular attention to all four.

The operationalization of theoretical constructs describes the correct specification of indicators of the concepts being studied. It bears the threat of subjectivity, which, in turn, should be exposed and reduced. In order to guarantee construct validity, we followed Yin's (2009) suggestions and implemented three methods. First, in data collection we used multiple sources of evidence. This included freely available documents on the Internet (e.g., publications on the website of the network or press releases), internal documents (e.g., formal documents on decision structures or IT support), semistructured interviews, and structured survey data. Moreover, in the first three case studies, we garnered data from two different organizations within each network in order to cross check the statements of the interviewees. However, our analyses revealed no differences. Second, we strictly followed a clear chain of evidence, starting with the initial research question and resulting in the ultimate conclusion. External observers should be able to trace our steps in both forward and backward directions. Third, three researchers were involved in the case analysis, which diminishes the risk of subjective judgments in the study. Reliability is a criterion that measures the repeatability of a study leading to the same results. The development of a case-study database and transparent documentation of the procedure are the major methods for improving reliability, which we have done for this study.

\section{Results from Case Studies}

In this section we present results from both the within-case analysis and the cross-case analysis. First, we analyzed the data provided for each case site. It was possible to match all case sites to a governance archetype. In total, we find one decentralized type, one hybrid type, and three centralized governance archetypes. We were also able to match instances of our contingencies factors to each case study with one exception. The codes for the variable IT competence are not applicable for Cases B, C, and D. Although prior studies such as Sambamurthy and Zmud (1999) report homogenous distribution of a high degree or low degree of IT competence, our results reveal a high discrepancy between the different organizations. For example, the members of AutoPartsNet (Case B) differ greatly in organizational size. Large organizations usually have a dedicated IT function, while smaller organizations often do not. Therefore, we marked these cases as "heterogeneous" and did not consider them in the later analysis. An exemplary description of Case $B$ can be found in Table 5 .

After we conducted the within-case analysis, we aggregated the data and compared them across all cases. Table 6 depicts the results from the cross-case analysis. For each instance of a contingency factor, we matched the corresponding governance type according to our contingency model. We also computed confirmation levels of the observed IT governance archetype and the contingency factors; we classified cases with 1-2 positive matches as low, cases with 3-4 matches as medium, and cases with 5-6 matches as high. In total, we found two cases with high confirmation levels, one with a medium confirmation level, and two with low confirmation levels. For example, in Case A four out of six contingency variables suggest that an centralized IT network governance is effective. Accordingly, it can be argued that a centralized mode would be the effective choice for network $A$ and, indeed, we observe that Case $A$ has a centralized governance mode. This confirmation can be interpreted as a high degree of fit between the contingency variables and the actual archetype of IT network governance. 


\section{Table 5 - Exemplary within-case analysis of case study $B$}

\section{Case study B: AutoPartsNet}

AutoPartsNet is a network of 15 independent vehicle-parts wholesalers, who supply to auto shops in different sales territories within Germany. AutoPartsNet functions as an umbrella organization of the network. This incorporated company has its shares equally distributed among the 15 members, but operates a companionship. The partnership was founded in 2000 as a simple purchasing cooperation. The most important aspect of the collaboration of the network is in the purchasing sector. Goods and services are purchased for reselling purposes and for the company itself. Additionally, concepts of repair shops are being sold to help customers of the wholesale dealer organize their repair shops. The support consists of numerous services such as insurance, rental cars, and IT systems for repair shop management. Network marketing actions such as print advertisement and a strong cooperation in the IT sector are also involved.

\begin{tabular}{l|l}
\hline IT support & $\begin{array}{l}\text { AutoPartsNet operates a catalogue and network-wide web-shop system that is integrated } \\
\text { into all merchandising management systems of all retailers, as well as the IT systems of the } \\
\text { customers (repair shops). A central article data-management system that works due to the } \\
\text { similar product lines of the networking members is already in use. Currently, an SAP-based } \\
\text { merchandising management system is planned and will soon be introduced. Additionally, } \\
\text { common distribution systems for the field staff will be introduced, as will the development } \\
\text { and performance of IT activities concerning repair-shop concepts. Groupware systems are } \\
\text { not yet used, though an intranet is supposed to be launched. A stronger and more compact } \\
\text { consolidation of cooperation within the network can be seen all in all. }\end{array}$ \\
\hline IT network & $\begin{array}{l}\text { Decisions concerning the IT are made in a 15-person board, where the IT directors of all } \\
\text { members participate. The director of IT management of AutoPartsNet leads this board and } \\
\text { initiates projects concerning the suggestions of the stockholders. Afterwards, a process is } \\
\text { initiated in which all IT directors find a solution on whether the proposed subject is needed or } \\
\text { not, which is then defined and presented. The decision is legitimate with a majority of votes } \\
\text { and covers all IT fields except investment and priority decisions. If a certain project needs } \\
\text { funding or a certain strategic decision must be made, the IT directors' board will work on a } \\
\text { solution in a shareholder conference with the 15 shareholders, and then finally a majority } \\
\text { vote decides the situation. }\end{array}$
\end{tabular}

\section{Contingency Factors}

\begin{tabular}{|l|l} 
1. Network size & The network comprises 15 vehicle-parts wholesalers, which can be classified as medium.
\end{tabular}

\begin{tabular}{l|l} 
2. Network & The overall structure of the network is centralized. The network established a dedicated
\end{tabular} governance $\quad$ legal construct with formalized decision structures. Decisions are made in meetings of all 15 member organizations that take place several times each year.

3. Trust between $\quad$ There is a high degree of trust between all involved organizations. They do not perceive partners $\quad$ opportunistic behavior of others as a threat. The trust in the network is expressed in a good community spirit and mirrored in good collaboration.

\begin{tabular}{l|l} 
4. Functional & The diversity of the different member organizations is low. All members are wholesalers of
\end{tabular} diversity $\quad$ vehicle parts. Despite different sizes of the companies and partial differences in their product ranges, core activities are similar.

5. IT infusion $\quad$ The strategic relevance of network-wide IT resources is high. Crucial business processes are supported by IT systems managed and provided by the central authority. For example, a common web shop already generates up to 15-20 percent of the revenue of some members.

6. IT competence $\quad$ The IT competence of the different members is heterogeneous and related to the size of the members. Large member organizations have a dedicated IT function, while small companies usually lack specifically trained personal.

IT governance $\quad$ All four areas of IT governance, i.e., cost-effective use, effective use for growth, asset effectiveness $\quad$ utilization, and business flexibility, are rated as important. The influence of IT governance for each dimension is also rated as high. Accordingly, the overall effectiveness is high. 
The Contingent Role of Centrality in IT Network Governance: An Empirical Examination/ Trang et al.

In three cases, we found a high degree of IT governance effectiveness, while we found one case with medium and one case with low governance effectiveness. Contingency theory posits that a high degree of fit between the contingent factors and the IS variable leads to effectiveness and, in turn, a low degree of fit results in a low degree of effectiveness. We are able to relate to this relationship in four cases; only Case $B$ does not follow this systematic.

\begin{tabular}{|c|c|c|c|c|c|}
\hline & \multicolumn{5}{|c|}{ Network } \\
\hline & Case A & Case B & Case C & Case D & Case $\mathrm{E}$ \\
\hline \multicolumn{6}{|l|}{ Contingency variables } \\
\hline Network size & Large (c) & Small (d) & Large $(\mathrm{c})$ & Medium (h) & Small (d) \\
\hline Network centralization & High (c) & High (c) & Medium (h) & $\operatorname{High}(\mathrm{c})$ & Low $(\mathrm{d})$ \\
\hline Functional diversity & Low (c) & Low (c) & Low $(c)$ & Medium $(\mathrm{h})$ & High (d) \\
\hline Network trust & High (d) & High (d) & Medium (h) & Low (c) & High (d) \\
\hline IT infusion & Medium $(\mathrm{h})$ & High (d) & Medium (h) & High (d) & High (d) \\
\hline IT competence & Low $(c)$ & Heterogeneous & Heterogeneous & Heterogeneous & High (d) \\
\hline \multicolumn{6}{|l|}{ IS variable } \\
\hline Observed archetype & Centralized & Centralized & Hybrid & Centralized & Decentralized \\
\hline \multicolumn{6}{|l|}{ Fit } \\
\hline Confirmation level & High & Low & Medium & Low & High \\
\hline \multicolumn{6}{|l|}{ Effectiveness } \\
\hline IT gov. effectiveness & High & High & Medium & Low & High \\
\hline
\end{tabular}

\section{Discussion}

The data collected at the five case sites support the basic structure of the research model. Contingency theory provides a solid theoretical foundation for the description and analysis of our research questions.

Research Question 1 asks to identify ITrelated decision making in network collaborations. We identified the degree of centralization as a relevant characteristic and described three distinct archetypes along this dimension, i.e., centralized, hybrid, and decentralized. With the data gathered through the case studies, we are able to identify each generic type at least once. Since we can ground our theoretical archetypes within real data, we see this as support for our conceptualization. Research Question 2 deals with the optimal degree of IT network governance centralization. Building upon contingency theory and prior work on intra-organizational IT governance and network governance, we argue that the optimal decision is dependent on six factors. The case study methodology allows us to go deeper into the causal mechanisms behind the contingency model, which we will discuss now.

First, our results indicate a gap between observed archetypes and the degree of centralization as proposed by the contingency factors. For example, Case $D$ is a medium sized network with a medium degree of functional diversity, which both favors hybrid governance. However, the IT infusion is low, which speaks for decentralized governance, while the observed governance mode is centralized. This discrepancy is not necessarily surprising since the overall effectiveness is rated as low. An explanation might be that governance modes are not a singular decision in time under the consideration of 
long-term effectiveness, but rather that evolution and path dependencies of a network lead to current practices (Sydow et al. 2009; Burger \& Sydow 2014). This could explain differences in the confirmation level. Our data also points in this direction; in all five cases we see that the degree of network centralization corresponds with the observed IT governance archetype. It is reasonable that, from a practical point of view, IT-related governance structures evolved along these existing structures. However, this evolutionary perspective is independent from considerations of IT network governance effectiveness.

While Cases A, C, D, and E follow the logic of contingency theory, i.e., the confirmation level relates to IT governance effectiveness, Case B cannot be directly explained by the research model. We find four reasons that might explain this phenomenon. First, the within-case analysis of AutoPartsNet reveals a high diffusion of trust among the members of the vehicle-parts wholesalers. As discussed in Section 3, a high degree of trust may make formalized decision structures dispensable and thus inefficient; however, a trusting atmosphere can also influence other favorable attributes in collaboration settings, such as motivation (El Khatib et al. 2013). This also fits the observation we made in Case $A$, in which the interviewees stated a generally positive influence of trust on collaboration. Second, a high degree of IT infusion as in the case of AutoPartsNet increases dependency on other members. As examined empirically in Chatterjee and Ravichandran (2013), organizations strive to gain individual control concerning the governance of interorganizational systems with a high degree of operational integration. The close and lasting cooperation in the case of AutoPartsNet may explain why the high degree of IT infusion does not lead to decentralized governance. The fear of vulnerability through dependency on other members may be reduced due to positive prior experiences. Third, the interviewees at AutoPartsNet especially underlined the benefits gained through functional integration. In contrast to, for example, a quantitative inquiry, our research design does not examine the relative importance of the factors compared to one another. Thus, the functional diversity factor may overcompensate for factors pointing in the other direction, which, in turn, can also explain the deviation between the fit of observed and proposed archetypes and IT governance effectiveness. Lastly, this inconsistency might be an indicator for supplementary contingency factors that are not included in our model, such as industry specific cultures.

As mentioned earlier, in three out of five cases we were not able to relate the contingency variable IT competence to the data gathered at the case sites. The interviewees state a high discrepancy in competence levels among the member organizations. This is in contrast to, e.g., Sambamurthy and Zmud (1999) who were able to find a homogeneous distribution of IT competence in non-IT divisions within companies. Although the two cases where we were able to assign an IT competence level show support for our proposed influence, more research is necessary to better understand the causal relation of this contingency.

This paper contributes to the body of literature on IT network governance in two ways. First, we developed a classification of three different archetypes. Translating the concept of centrality from intraorganizational governance to the network level, we demonstrated that this is also an important characteristic in interorganizational IT governance. This more differentiated perspective extends prior studies on IT-related governance structures, such as Chong and Tan (Chong \& Tan 2012) or Prasad et al. (2011). In particular, our findings indicate that inter-organizational networks significantly differ in terms of their IT governance arrangements, which reflects in the design and configuration of IT related network structures, processes, and collaborative relationships. Second, building 
The Contingent Role of Centrality in IT Network Governance: An Empirical Examination/ Trang et al.

upon this classification, we contributed a contingent perspective on IT governance structures in inter-organizational networks. This addresses a research gap explicitly identified by De Haes and Van Grembergen (2012). Our findings emphasize that there is no single best solution to govern IT in networks; the choice for an optimal governance mode should rather be made under the consideration of internal and external factors. For practitioners, this study provides background on how to effectively coordinate their IT-related decision making. Furthermore, this study offers descriptions of alternative governance modes as well as explanations for why a specific degree of centralization in decision making is efficient. Network managers should reflect their ITrelated governance arrangement in order to become salient in directing their interorganizational IT resources.

However, results we derived from our data must be interpreted with caution. First of all, our case study research design does not allow for generalization. Although our theoretical sampling follows a diverse case strategy, which is said to have stronger claims to representativeness than any other small-N sample technique, more empirical work is necessary to validate our propositions. Moreover, Case $\mathrm{C}$ and $\mathrm{D}$ have a similar branch context; however, we decided to include both in order to broaden the analysis. Second, we do not claim the selection of relevant contingencies to be complete; we chose this set of factors after a careful review of existing knowledge in the field of network governance and IT governance and included the most salient ones. Further factors, e.g., with a focus on platform technologies which cover security and availability aspects for the network, may also be revealed as relevant. Third, this research model argues along a singular contingency analysis (Brown \& Grant 2005); dependencies and interactions among the factors are neglected. Future studies on IT network governance should expand this perspective and consider mutual influences (e.g., Sambamurthy \& Zmud 1999). Fourth, we argue that the degree of centrality, as a typical characteristic of structures of ITrelated decision making, can be classified along the dimension from highly centralized to highly decentralized. Although we were able to observe the proposed archetypes, more relevant characteristics might exist. Thus, explorative research is needed in order to identify further potential characteristics of IT-related decision making. Finally, according to our research model, we propose that IT governance effectiveness directly influences network performance. However, previous research in both intraorganizational (Wu et al., 2015) and interorganizational (Trang et al., 2014) contexts postulates that this causal link is also mediated by different key antecedents of organizational and inter-organizational performance.

\section{Conclusion}

This paper contributes to the emerging field of IT network governance. First, we identify the degree of centrality as an important characteristic of decision making and, building upon this, develop three distinct governance archetypes. Second, we use this classification and develop a model that argues through the lens of contingency theory, that IT network governance effectiveness is dependent on six factors: network size, network centralization, functional diversity, trust, IT infusion, and IT competence. While data gathered through five case studies show general support of both the theoretical archetypes and the contingency model, we found that IT competence cannot as expected be directly translated from the intra- to the interorganizational level and needs further refinement in operationalization and causality.

This paper is a first step towards a more differentiated perspective on contingent governance structures in interorganizational networks. While the multiple case study methodology allowed us to delve deeper into causal mechanisms behind the theoretical relationships, further quantitative 
research is necessary to triangulate the findings. Practitioners such as network managers should reflect their current ITrelated governance arrangements according to the contingency factors identified in this study.

\section{Acknowledgments}

The authors thank Ting-Peng Liang and two anonymous reviewers for their thoughtful comments. A prior version of this paper has been published in the PACIS 2014 proceedings. The authors thank the participants of the Accounting and Information Technology track for their valuable feedback. This research was supported by the German Research Foundation (DFG), grant GRK 1703/1 for the Research Training Group "Resource Efficiency in Inter-organizational Networks Planning Methods to Utilize Renewable Resources."

\section{References}

Alter, C. \& Hage, J., 1993. Organizations Working Together, Newbury Park, California: Sage Publications.

Brown, A.E. \& Grant, G.G., 2005. Framing the Frameworks: a Review of IT Governance Research. Communications of the Association for Information Systems, 15(1), pp.696712.

Brown, C. V \& Magill, S.L., 1998. Reconceptualizing the Context-Design Issue for the Information Systems Function. Organization Science, 9(2), pp.176-194.

Burger, M. \& Sydow, J., 2014. How Interorganizational Networks Can Become Path-dependent: Bargaining Practices in the Photonics Industry. Schmalenbach Business Review, 66(1), pp.73-99.

Chatterjee, D. \& Ravichandran, T., 2013. Governance of Interorganizational Information Systems: A Resource Dependence Perspective. Information
Systems Research, 24(2), pp.261278.

Chong, J.L.L. \& Tan, P.F.B., 2012. IT Governance in Collaborative Networks: A Socio-Technical Perspective. Pacific Asia Journal of the Association for Information Systems, 4(2), pp.30-48.

Croteau, A. \& Bergeron, F., 2009. Interorganizational Governance of Information Technology. In Proceedings of the 42nd Hawaii International Conference on System Sciences.

Dowse, A. \& Lewis, E., 2009. Applying Organizational Theories to Realize Adaptive IT Governance and Service Management. In Information Technology Governance and Service Management. Frameworks and Adaptions. Hershey, pp. 313-331.

Ein-dor, B.P. \& Segev, E., 1982. Organizational Context and MIS Structure: Some Empirical Evidence. Management Information Systems Quarterly, 6(3), pp.55-68.

Eisenhardt, K.M., 1989. Building Theories from Case Study Research A. M. Huberman \& M. B. Miles, eds. Academy of Management Review, 14(4), pp.532-550.

Faerman, S.R., Mccaffrey, D.P. \& Slyke, D.M. Van, 2001. Understanding Interorganizational Cooperation: Public-Private Collaboration in Regulating Financial Market Innovation. Organization Science, 12(3), pp.372-388.

Grant, G. \& Tan, F.B., 2013. Governing IT in Inter-organizational Relationships: Issues and Future Research. European Journal of Information Systems, 22(5), pp.493-497.

De Haes, S. \& Van Grembergen, W., 2012. Inter-Organizational Governance of Information Technology: Learning from a Global Multi-Business-Unit Environment. International Journal of 
The Contingent Role of Centrality in IT Network Governance: An Empirical Examination/ Trang et al.

IT/Business Alignment and Governance, 3(1), pp.25-44.

El Khatib, V. et al., 2013. The Role Of Motivational Factors In Distributed Software Development Teams: An Empirical Investigation. In Proceedings of the 21st European Conference on Information Systems. Utrecht.

King, N., 2013. Exploring the Impact of Operating Model Choice on the Governance of Inter-Organizational Workflow: the U.S. E-Prescribing Network. European Journal of Information Systems, 22(5), pp.548568 .

Lawrence, P.R. \& Lorsch, J.W., 1967. Differentiation and Integration in Complex

Administrative Science Quarterly, 12(1), pp.1-47.

Markus, M.L. \& Bui, Q. “Neo,” 2012. Going Concerns: The Governance of Interorganizational Coordination Hubs. Journal of Management Information Systems, 28(4), pp.163-198.

Mayring, P., 2007. Qualitative Inhaltsanalyse. Grundlagen und Techniken 9th ed., Weinheim: Deutscher Studien Verlag.

McEvily, B., Perrone, V. \& Zaheer, A., 2003. Trust as an Organizing Principle. Organization Science, 14(1), pp.91103.

Paré, G., 2004. Investigating Information Systems with Positivist Case Study Research. Communications of the Association for Information Systems, 13, pp.233-264.

Peterson, R.R., 2004. Integration Strategies and Tactics for Information Technology Governance. In W. Van Grembergen, ed. Strategies for Information Technology Governance. Hershey: Idea Group Puplishing, pp. 37-80.
Powell, W., 1990. Neither Market nor Hierarchy: Network Forms of Organization. Research in Organizational Behaviour, 12, pp.295336.

Prasad, A., Green, P. \& Heales, J., 2011. IT Governance in Collaborative Organizational Structures. In Proceedings of the 17th Americas Conference on Information Systems. Detroit.

Prasad, A., Green, P. \& Heales, J., 2013. On Governing Collaborative Information Technology (IT): A Relational Perspective. Journal of Information Systems, 27(1), pp.237259.

Provan, K.G. \& Kenis, P., 2008. Modes of Network Governance: Structure, Management, and Effectiveness. Journal of Public Administration Research and Theory, 18(2), pp.229252.

Sambamurthy, V. \& Zmud, R.W., 1999. Arrangements for Information Technology Governance: A Theory of Multiple Contingencies. Management Information Systems Quarterly, 23(2), pp.261-290.

Span, K.C.L. et al., 2011. The Relationship Between Governance Roles and Performance in Local Public Interorganizational Networks: A Conceptual Analysis. The American Review of Public Administration, 42(2), pp.186-201.

Staber, U., 1998. Inter-firm Co-operation and Competition in Industrial Districts. Organization Studies, 19(4), pp.701724.

Sullivan, C.H., 1985. Systems Planning in the Information Age. Sloan Management Review, 26(2), pp.3-12.

Sydow, J., Schreyögg, G. \& Koch, J., 2009. Organizational Path Dependence: Opening the Black Box. Academy of 
Management Review, 34(4), pp.689709 .

Tavakolian, H., 1989. Linking the Information Technology Structure with Organizational Competitive Strategy: a Survey. Management Information Systems Quarterly, 13(3), pp.309-317.

Trang, S.T.-N., Opitz, N. \& Kolbe, L.M., 2013. IT Governance in a Network Context: Literature Review and Agenda for Research. In Proceedings of the 19th Americas Conference on Information Systems.

Trang, S.T.-N., Zander, S. \& Kolbe, L.M., 2014. Examining IT Alignment in Interorganizational Networks: Development and Application of a Measurement Instrument. In Proceedings of the 18th Pacific Asian Conference on Information Systems.

Venkatraman, N., 1989. The Concept of Fit in Strategy Research: Toward Verbal and Statistical Correspondence. Academy of Management Review, 14(3), pp.423-444.

Ward, J. \& Peppard, J.O.E., 2002. Strategic Planning for Information Systems 3rd ed., New York: John Wiley \& Sons.

Weill, P. \& Olson, M.H., 1989. An Assessment of the Contingency Theory of Management Information Systems. Journal of Management Information Systems, 6(1), pp.59-85.

Weill, P. \& Ross, J.W., 2004. IT Governance: How Top Performers Manage IT Decision Rights for Superior Results, Harvard: Harvard Press.

Wu, S., Straub, D. \& Liang, T.-P., 2015. How Information Technology Governance Mechanisms and Strategic Alignment Influence Organizational Performance: Insights from a Matched Survey of Business and IT Managers. Management Information Systems Quarterly, forthcoming.
Xiao, J., Xie, K. \& Hu, Q., 2013. Inter-Firm IT governance in Power-Imbalanced Buyer-Supplier Dyads: Exploring How it Works and Why it Lasts. European Journal of Information Systems, 22(5), pp.512-528.

Yin, R.K., 2009. Case Study Research: Design and Methods,

Zaheer, A., McEvily, B. \& Perrone, V., 1998. Does Trust Matter? Exploring the Effects of Interorganizational and Interpersonal Trust on Performance. Organization Science, 9(2), pp.141159.

Zarvić, N. et al., 2012. Dependency-Based IT Governance Practices in InterOrganizational Collaborations: A Graph-Driven Elaboration. International Journal of Information Management, 32(6), pp.541-549.

\section{About the authors}

Simon Trang is a research member and Ph.D. candidate at the DFG research training group 1703 at Göttingen University. He studied information systems at Göttingen University, Aarhus University, and Seoul National University and received his master's degree in 2011. His research interests interface between information systems, strategic management, and ecological sustainability. His work has been published or is forthcoming in leading IS conferences and journals such as the International Conference on Information Systems, the European Conference on Information Systems, Hawaii International Conference on System Sciences, and Journal of Cleaner Production.

Sebastian Zander is a research associate under the Chair of Information Management at the University of Göttingen. $\mathrm{He}$ is a research member and Ph.D. candidate at DFG research training Group 1703 "Resource Efficiency in Interorganizational Networks - Planning Methods to Utilize Renewable Resources". He studied 
The Contingent Role of Centrality in IT Network Governance: An Empirical Examination/ Trang et al.

management with thematic priority on information systems and received his master's degree in 2013. His current research interest is focused on the role of information systems in facilitating the efficient processing and utilization of renewable raw materials across organizational boundaries. Previous work has been published in leading IS conference proceedings, such as HICSS and ICIS.

Lutz M. Kolbe is a full professor and Chair of Information Management at the GeorgAugust-University of Göttingen, Germany since 2007. Lutz completed an apprenticeship in banking and received his degree in Information Systems from the Technical University Braunschweig, Germany. At the Technical University Freiberg, Germany, he earned his doctorate in Business Administration. Subsequently, he led Deutsche Bank's IT think tanks in Frankfurt, New York, and San Francisco. In 2002 he moved on to the Institute of Information Systems at the University of St. Gallen, Switzerland, as head of several competence centers. He was also a visiting scholar at the University of Rhode Island, New York University, and IBM Research Almaden (USA). His main research interests are Green IS, IT Management, and Sustainable Mobility. 